\title{
Grid-forming control strategies for black start by offshore wind power plants
}

\author{
Anubhav Jain ${ }^{1}$, Jayachandra N. Sakamuri ${ }^{2}$, and Nicolaos A. Cutululis ${ }^{1}$ \\ ${ }^{1}$ DTU Wind Energy, Technical University of Denmark, 4000 Roskilde, Denmark \\ ${ }^{2}$ Vattenfall A/S, 6000 Kolding, Denmark \\ Correspondence: Anubhav Jain (anub@dtu.dk)
}

Received: 31 January 2020 - Discussion started: 17 March 2020

Revised: 4 June 2020 - Accepted: 13 August 2020 - Published: 12 October 2020

\begin{abstract}
Large-scale integration of renewable energy sources with power-electronic converters is pushing the power system closer to its dynamic stability limit. This has increased the risk of wide-area blackouts. Thus, the changing generation profile in the power system necessitates the use of alternate sources of energy such as wind power plants, to provide black-start services in the future. However, this requires grid-forming and not the traditionally prevalent grid-following wind turbines. This paper introduces the general working principle of grid-forming control and examines four of such control schemes. To compare their performance, a simulation study has been carried out for the different stages of energization of onshore load by a high-voltage directcurrent (HVDC)-connected wind power plant. Their transient behaviour during transformer inrush, converter pre-charging and de-blocking, and onshore block-load pickup has been compared and analysed qualitatively to highlight the advantages and disadvantages of each control strategy.
\end{abstract}

\section{Introduction}

Environmental problems like global warming, coupled with increasing fuel prices and the global drive towards sustainable development with energy security, have accelerated the integration of renewable energy sources into power systems all around the world. Many countries have set out several energy strategies for a more secure, sustainable, and low-carbon economy like the European Union's (EU) 2018 (RED II) directive on the promotion of the use of energy from renewable sources that sets an overall goal across the EU for a $32 \%$ share of renewables in the total energy consumption by 2030. Among the different renewable energy sources, wind energy has seen a rapid growth in the installed capacity worldwide, from about $6.1 \mathrm{GW}$ in 1996 to about $591.5 \mathrm{GW}$ in 2018 (Tavner, 2012), showing huge promise as one of the major electricity sources in the future.

High-volume integration of renewable energy into the power system makes it harder to maintain reliability and stability of power supply in the grid due to introduction of variable power flows and thus complicating grid operation (De Boeck et al., 2016). Moreover, the decrease in reactive power reserve due to replacement of conventional synchronous generation destabilizes the long-distance transmission corridors between load centres and large-scale renewable energy systems - such as offshore wind power plants (OWPPs) - during system contingencies (Sarkar et al., 2018). Additionally, inertial decoupling from the grid by the power electronic converter (PEC) interface results in decreased transient stability, increasing the risk of wide-area blackouts, especially in strongly linked networks (De Boeck et al., 2016). For example, as per Australian Energy Market Operator, the failure of WPP owners to comply with performance requirements to ride through major disruptions and disturbances led to blackout of the South Australia system (Australian Energy Market Operator, 2017), affecting about 850000 people and causing large-scale disruption to their livelihood and the economy. Another very recent case is the unexpected reduction of 737 MW from Hornsea 1 OWPP in the UK, which is cited to be one of the main causes of the system failure in August 2019, affecting about 1 million customers and causing travel chaos in and around London, according to the technical report by National Grid (2019a). 


\subsection{The changing paradigm}

Traditionally black-start service has been provided mainly by coal- or gas-fired generators and pumped-hydro storage due to their capability to meet all the technical requirements (Elia, 2018; National Grid, 2019b). However, due to the societal decarbonization aims, rising fuel costs coupled with ageing assets, and decreasing load factors, large conventional generation plants are being phased out in favour of renewables and non-traditional technologies, which increases the cost of warming up large generators, and consequently of black-start services (National Grid, 2019b). Since maintaining the status quo for black start and restoration is not an option, considerable changes are required to facilitate the participation of alternate sources like renewable energy and nontraditional technologies in the black-start market given the modern evolving energy landscape. Elia and National Grid, for example, have recently confirmed that there is a potential to open up the delivery of black-start service to interconnectors, sites with trip-to-house load operation, and aggregated units including variable generation (like wind, solar), especially with support from energy storage systems.

Black start and islanding operation requirements have been included as options for WPPs in the ENTSO-E network codes, where the relevant system operator is allowed to request these functions to support grid recovery (Göksu et al., 2017). Driven by grid codes, state-of-the-art wind turbines (WTs) are already capable of providing some services that are a part of the restoration process - e.g. fast frequency response and low-voltage ride-through (LVRT) - and are expected to deliver more advanced requirements like inertia emulation, power oscillation damping, and reactive current injection, which are increasingly being demanded by grid codes (Jain et al., 2019). This is possible due to the advanced functionalities of the full-scale PEC interface of modern WTs, as mentioned in Chen et al. (2009). Seca et al. (2013) show that WTs owing to their fast start-up times can be included earlier in the restoration process to provide reactivepower support and pickup load, thus decreasing the impact of a blackout event by reducing the restoration time and unserved load. However, connection of the currently prevalent grid-following (GFL) WTs in the beginning of the restoration procedure can cause a recurrence of blackout as the grid is generally not stable enough (El-Zonkoly, 2015). The early participation of WPPs in successful bottom-up network energization can be facilitated instead by grid-forming (GFM) control of WTs, allowing them to operate together as an AC voltage source without relying on an external grid, and supply load in a power island.

GFM control of converters to integrate renewables at the distribution level has been extensively researched for microgrids. However, only recently has it begun being applied to high-power applications. To the authors' knowledge, there are not enough in-depth studies addressing black-start energization by high-power GFM renewable sources connected at the transmission level. Even at the distribution level, it is only recently - due to risks of uncontrolled islanding - that research has been conducted on microgrid islanding capabilities provided by GFM converters, for defence against blackouts in future power systems (Rocabert et al., 2012). Moreover, most existing microgrids are AC systems, with DC systems only now gaining momentum as they allow higher operational and control flexibility of the microgrid, enhancing its role in maintaining the reliability of future power grids (Arbab-Zavar et al., 2019).

\subsection{Contribution}

This study investigates the black-start capability of a GFM OWPP, connected via high voltage, direct current - a challenging scenario due to not only faster energization transients but also more active components - and controlled with different grid-forming schemes, to compare their transient behaviour in such a challenging black-start setup. The aim is to characterize the different techniques and compare their capability to deal with the energization transients in a controlled manner while maintaining stable voltage and frequency at the offshore terminal. There exist only a handful of such studies - on black start by high-voltage-AC/DC-connected GFM OWPPs - however, they choose one GFM method and focus on different aspects of the restoration process. In general, this paper aims at covering the lack of literature comparing the different grid-forming control strategies - typically developed for general purposes and driven by microgrid research - in a specific and demanding task such as a wind power plant providing black-start services. While non-exhaustive, we think that this comparison can help direct future research in this area. To the authors' knowledge, such a study has not been done before.

In the next section of the paper, the state of the art of the role of wind energy in power system restoration has been reviewed. This is followed by an explanation of the general working principle of GFM control, along with a conceptual comparison of the four different control strategies considered for this study - on the energization of onshore load by an HVDC-connected GFM OWPP. Then the PSCAD model of the point-to-point HVDC-connected OWPP is described along with the different stages in the simulation of the energization sequence. Finally the transient behaviour of the different control techniques during the various stages of energization are presented and discussed.

\section{Wind energy for black start - literature review}

Large OWPPs can provide fast and fully controlled, highpower, emission-free green black-start services but there exists a gap between the present grid-code black-start requirements and current WT black-start capabilities as identified by Jain et al. (2019). Technological changes are needed to make WTs black-start ready/able, and the technical chal- 
lenges associated with the different stages of energization of an HVDC-connected OWPP, along with control techniques to mitigate those issues, have been discussed by Jain et al. (2018). A recent report by National Grid (2019b) also summarizes the technological capability of non-traditional technologies like renewables and distributed energy sources to provide black-start and restoration services. In the following, literature studies on WPPs - with different topologies participating in power system restoration are presented, highlighting the associated research gaps.

\subsection{WPP and a voltage source hybrid}

Traditional GFL WTs can be used with an external power supply (e.g. diesel generator or energy storage) and a synchronous var generator (SVG) or STATCOM, combining services into a joint/hybrid black-start unit to facilitate WT participation in black-start procedure as proposed in Aktarujjaman et al. (2006). The external supply provides startup power and sets the reference voltage and frequency for the isolated system, the SVG/STATCOM supports the var requirement of the cables and transformers and stabilizes the voltage, after which the WTs connect to meet the load power demand. Zhu et al. (2018) show that earlier participation of WTs in the restoration procedure is feasible as GFM control allows black-start and stand-alone island operation with better inherent synchronous-machine-like inertial response during a transient that can help absorb the initial impact of energization and ensure smooth load pickup, thus mitigating large voltage/frequency excursions that might occur during restoration. However, only the transients during load pickup and resynchronization to the grid have been studied, while energization of collector lines, export cables, and transformers, which present more challenges to transient stability during energization, are not shown. Additionally the major energization transients are dealt by the energy storage system and SVG, while the WTs behave only as passive GFL power sources to meet the load demand during the last stages of restoration.

\subsection{HVAC-connected WPP}

Recent studies by Martínez-Turégano et al. (2018) and Aten et al. (2019) demonstrate the potential capability of highvoltage alternating current (HVAC)-connected OWPPs to black-start the onshore grid using GFM controls in less than $25 \%$ WTs and assuming adequate wind resource. The results show that it is possible to do sequential energization of the array cables and WT transformers, starting with one WT energizing its string followed by others synchronizing to it and then sharing the control of voltage and frequency. Shorter cable sections are energized first until enough WTs are connected to absorb the var generated by subsequent cable sections. However, according to Elia (2018) and National
Grid (2019b), a large gap to bridge is the energization of the export link while meeting grid code requirements.

\subsection{HVDC-connected WPP}

HVDC with voltage source converters (VSCs) can also be used as a standby facility for black start and restoration of the onshore AC grid, as demonstrated by the excellent voltage and frequency control performance in real system tests done by Jiang-Hafner et al. (2008), proving for the first time that VSC-HVDC helps reduce restoration time while facilitating a safer and smoother restoration process with lower investment and maintenance cost. With HVDC transmission gaining momentum as the preferred choice for longer distance connections to larger OWPPs, Sørensen et al. (2019) show that the Skagerrak-4 VSC-HVDC link between Norway and Denmark (DK) can be successfully used to ramp up the voltage of an islanded $400 / 150 \mathrm{kV}$ DK network to energize overhead transmission lines, transformers, and block load, followed by synchronization to the continental EU. Additionally, a top-down restoration test of the NEMO link between Belgium and the UK also demonstrates the capability of the VSC-HVDC interconnector to energize a dead Belgian grid from the live UK side (Schyvens, 2019).

Simulation results by Becker et al. (2017) show, although without any details of the transformer-cable energization transients, that a VSC-HVDC-connected OWPP can respond to onshore load changes and participate in load restoration. Cai et al. (2017) analyse the inrush current of transformers and cables (HVAC and HVDC) using electromagnetic transient simulations, but with a diesel generator to pre-charge the offshore converter that then energizes the offshore collector grid and the onshore converter pre-charged by the onshore AC grid, contrary to what is expected from an OWPP to provide black-start service. Simulation results presented by Sakamuri et al. (2019) demonstrate, for the first time, an HVDC-connected OWPP with GFM control, sequentially energizing the offshore AC network including transformer, cables, and converter through a pre-insertion resistor, followed by HVDC link energization and onshore converter pre-charging and de-blocking for picking up block load, successfully participating in restoration as a black-start unit. However, the energy imbalance in the HVDC link during the DC-side uncontrolled pre-charging of the onshore converter leads to a significant dip in HVDC voltage and large transients in the offshore and onshore converter cell voltages and valve currents.

In addition to enabling black-start and islanding capabilities of WTs, GFM control can also allow the use of hybrid HVDC connection with a diode rectifier unit (DRU) instead of the offshore VSC. The application of controls proposed in Blasco-Gimenez et al. (2010) for an OWPP to ramp up the offshore AC grid voltage and control frequency, considering it to be an inverter-based microgrid, has shown improved steady-state regulation during islanding when the 
DRU-HVDC is not conducting and smooth transition to current-control mode during grid-connected operation. This significantly reduces the cost vs. performance, due to lower losses (especially for higher power levels) and lesser capital cost, along with increasing efficiency and reliability due to a lower probability of commutation failure than a VSC (Andersen and $\mathrm{Xu}, 2004)$.

\section{Grid-forming control}

The current turbine and converter controls are designed assuming a strong grid connection point which means that the grid-side converter of the WT latches onto a pre-existing voltage signal provided by the onshore grid in the case of an AC-connected OWPP, or produced by the offshore HVDC converter operating in voltage-frequency control mode in the case of HVDC-connected OWPP (Bahrman and Bjorklund, 2014). However, to allow outward energization of the network of inter-array cables and transformers, a power island should be created that can supply local loads and energize the HVDC link converters and export cable with the ultimate aim to supply onshore block load; the WT should be able to produce its own voltage signal. This requires GFM control, traditionally referred to as voltage-injecting control, as opposed to the conventional GFL or current-injecting control. The two control philosophies are very well explained by Rocabert et al. (2012). GFM WTs can also minimize the use of diesel generators that are currently employed offshore to supply backup auxiliary power required for energization. Although most modern WTs have an on-board UPS to power communications, as well as provide protection and control for a few hours during emergency shutdown (Göksu et al., 2017), a larger internal backup supply may be required for self-starting the WT for black start, especially after extended shutdown periods.

GFM control of PECs has been well studied for microgrids, where the role of the converter is to act as an interface between the small-scale distributed/renewable power generation units and the consumption points, leading to inertial decoupling of the rotating machines and making the microgrid system susceptible to oscillations caused by network disturbances. GFM allows a PEC to mimic synchronous generators for droop-based load-sharing, synthetic-inertia emulation, synchronized and stand-alone operation, and blackstart behaviour, ensuring voltage and frequency stability in low-inertia microgrids during varying loads, network disturbances, and system configurational changes, e.g. between islanded and grid-connected modes (Tayyebi et al., 2018).

An OWPP is like a microgrid rich in power electronics, although very different in that the voltage and power levels are much higher. Moreover, OWPP operators maintain a large number $(>100 \mathrm{~s})$ of WT assets that are located very far from each other. Current-sharing techniques for low-rated inverters like the centralized controllers and the master-slave approach can be used only for paralleled systems that are close to each other and interconnected through high-bandwidth communication channels (Rocabert et al., 2012). These communication-based solutions cannot be used for microgrids spread across several kilometres, as ensuring globally available, bidirectional, reliable, robust, low-power, and secure communication architecture becomes increasingly costly. Moreover, longer links increase delays, which is undesirable in cases where a fast (high-bandwidth) communication is required. This gave way to droop control algorithms with a hierarchical structure being used in microgrids, especially for islanded operation of many micro-sources located far away from each other (Pogaku et al., 2007). Although rated at much lower power, these GFM droop-based strategies can be extended to high-power WTs for stable distributed operation in islanded mode, at variable loads and wind speeds, as demonstrated by Kanellos and Hatziargyriou (2008) and also Blasco-Gimenez et al. (2010).

\subsection{Control structure}

According to the definition in Rocabert et al. (2012), GFM converters are controlled in closed loop to work as ideal AC voltage sources (low-output impedance), while GFL converters are controlled as current sources with high parallel output impedance and cannot operate in islanding or stand-alone mode as they require a GFM converter or local synchronous generator to set the bus voltage and frequency.

The structure of GFM control consists of different functional blocks, as shown in Fig. 1. The main objective of GFM control is to operate the VSC as an ideal AC voltage source of a given amplitude $V_{0}$ and frequency $\omega_{0}$. This requires most importantly a voltage control loop $C_{\mathrm{V}}$. The shortcomings of the single-loop approach, explained in Zeni et al. (2015), are already known from switch-mode power supplies and electrical machine drives as overcurrents during transients, and faults cannot be limited due to the lack of an explicit closed-loop current controller. Additionally sensitivity to disturbances and plant-parameter fluctuations eliminates openloop control as a good choice. The most commonly used alternative is thus the nested or cascaded voltage-current controller, in which a faster inner current control loop $C_{\mathrm{I}}$ is added (Zeni et al., 2015). $C_{\mathrm{I}}$ is designed to have a relatively smaller time constant than $C_{\mathrm{V}}$ for decoupling the control loops. The controllers are in the synchronous reference frame that uses an angle $\theta^{*}$ (for $a b c \rightleftharpoons d q$ transformation) obtained from the synchronization block (Green and Prodanović, 2007).

While grid-feeding converters require perfect synchronism with the voltage at the point of connection to accurately regulate the power exchange with the grid, in the case of GFM converters the synchronization system must provide precise signals for both islanded and grid-connected modes of operation. It works as a fixed-frequency oscillator in the former case, while it slowly varies the phase angle and frequency of 


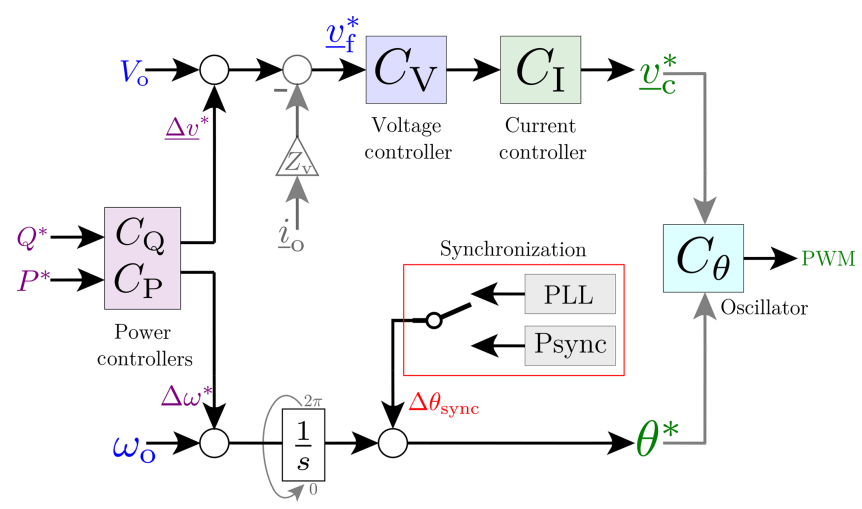

Figure 1. Grid-forming control structure consisting of current control loop $C_{\mathrm{I}}$, the voltage controller $C_{\mathrm{V}}$, and outer real/reactive power control loops $C_{\mathrm{P}, \mathrm{Q}}$.

the island voltage during the reconnection transient to resynchronize with the grid voltage, in the latter. The most extended method used in grid-connected operation is a phaselocked loop (PLL), also called voltage-based synchronization as the frequency and phase angle of the grid voltage vector is used for control. However, enhancements are needed to ensure stability under unbalanced and distorted voltage conditions as voltage sag, weak grids, or off-grid operation can lead to instabilities. Alternatively power-based synchronization can also be used as the structure of the swing equation that governs synchronous machine dynamics and can be equated to that of a PLL, in the sense that the PLL structure can be modified to extract the derivative term of the frequency ( $\sim$ inertia) and the speed variation ( $\sim$ damping), as shown in van Wesenbeeck et al. (2009). This presents a more stable solution and allows the power controller to also act as the synchronization block.

The outer power control loops $C_{\mathrm{P}, \mathrm{Q}}$ are required to regulate the real $(P)$ and reactive $(Q)$ powers exchanged with the grid (in grid-connected mode) or meet the demand set by the load (in islanded mode), while ensuring communicationless power sharing between the multiple paralleled inverters. The simplest method for this, by only relying on local measurements, is the droop control scheme, which was initially introduced for synchronous generators in utility scale grids, and now is well incorporated into microgrids (ArbabZavar et al., 2019). The primary level of the three-level hierarchical control, explained in Guerrero et al. (2011), employs droop control equations, based on interconnecting impedance $X / R$ ratio, to mimic the self-regulation capability of a grid-connected synchronous generators and allow power sharing in microgrids without using critical communication links (Rocabert et al., 2012).

Although easy to implement with high reliability and flexibility, traditional droop control suffers from an inherent trade-off between load sharing and voltage regulation, loaddependent frequency deviation, slow dynamic response due to filters for power measurement, and non-linear load-sharing issues due to harmonics. A variable virtual impedance $Z_{\mathrm{V}}$ can be used to add harmonic droop characteristics with additional damping and improve trade-off between current harmonic sharing and voltage total harmonic distortion by adjusting the output impedance seen at different frequencies. Additionally this allows intelligent mode switching with soft start to take advantage of the fast converter response while avoiding large transients (Guerrero et al., 2011). In the last decade, several different GFM control schemes have been proposed in literature, of which four have been chosen for this study and explained in the next section.

\subsection{Control strategies}

The traditional droop-based power controllers can be replaced with more complex controls to replicate the systemlevel functionalities of synchronous generators like inertia and damping characteristics, frequency and voltage droop, self-organizing parallel operation, and automatic power sharing. The virtual synchronous machine (VISMA) concept, introduced by Beck and Hesse (2007), uses power-based synchronization with a detailed implementation of the electromechanical model of a synchronous machine in its power control loop. This eliminates the need for PLL and allows conventional and proven grid operation with the usual static and dynamic properties that are characteristic to synchronous generators (both desired and undesired). Different detail levels of the VISMA implementation are listed in D'Arco and Suul (2013), while Lu and Cutululis (2019) give a review of different control methods that mimic the operation of a rotating synchronous machine, for example Synchronverter (Zhong and Weiss, 2009), and PLL-based swing-equation emulation (van Wesenbeeck et al., 2009). Moreover, improvements have been made to the VISMA concept; for example recently, non-linear control-based GFM strategies relying on the duality between PECs and synchronous machines have been proposed. This includes machine matching (Arghir et al., 2018) and virtual oscillator control (Johnson et al., 2017), which provide steady-state droop-like behaviour with a faster and better damped response during transients.

\subsubsection{Virtual synchronous generator (VSG)}

The virtual synchronous machine concept implemented here, shown in Fig. 2a, is based on D'Arco et al. (2015a). It uses standard cascaded voltage-current control in the synchronous rotating $d q$ reference frame for voltage control and current limitation. The behaviour of a synchronous machine is mimicked by using the swing equation - see Eq. (1) for power control. This also helps in power synchronization by generating the frequency reference and synchronization angle to control real power exchange with the grid, similar to a synchronous generator. The reactive power controller is 
based on standard inductive line $Q-V$ droop, which adjusts the voltage amplitude reference for controlling the reactive power exchange with the grid. A virtual resistance is added to reduce sensitivity to small grid disturbances by providing additional damping and to reduce the synchronous oscillations of droop-controlled converters (Sun et al., 2019). The swing equation controller, essentially a low-pass filter, can be replaced with proportional-integral-derivative/leadlag controllers, for enhanced electromechanical dynamics, adjustable characteristics like independent tuning of inertia, damping and steady-state droop, or highly non-linear behaviour during grid faults and connection-disconnection processes (Sun et al., 2019).

\subsubsection{Power synchronization control (PSC)}

The power synchronization law presented in VSG above uses the swing equation where the power difference drives the rotor speed dynamics, which is then integrated to get the electrical angle, i.e. double integration for the $P-\theta$ transfer function. This can be simplified using the PSC control structure explained in Zhang (2010), as shown in Fig. 2b. Here the phase angle is directly obtained by a single integration of the power difference, as given in Eq. (2). Due to one fewer integrator, PSC has a higher stability margin. However, no virtual inertia or damping is present due to absence of rotor dynamics.

$$
\begin{aligned}
P_{\mathrm{m}}-P_{\mathrm{e}}=J \omega_{0} \frac{\mathrm{d} \Delta \omega}{\mathrm{d} t}+D \omega_{0} \Delta \omega & , \quad \frac{\mathrm{d} \Delta \theta}{\mathrm{d} t}=\Delta \omega \\
& \Longleftarrow \text { swing equation }
\end{aligned}
$$

$\frac{\mathrm{d} \Delta \theta}{\mathrm{d} t}=k_{\mathrm{p}}\left(P_{\mathrm{ref}}-P\right) \Longleftarrow$ power synchronization law

The voltage control is governed by Eq. (3), where an $\mathrm{AC}$ voltage controller (AVC) is used similarly to the exciter of a synchronous machine, except with integral control instead of the typical proportional control, as shown in Fig. 2b, to suppress high-frequency disturbances. Active damping of the grid-frequency resonant poles is additionally implemented using a high-pass filter $H_{\mathrm{HP}}(s)$, described by Eq. (4), in the current reference-generating block, given by Eq. (5).

$\underline{v}_{\mathrm{C}}^{*}=\left(V_{0}+\underline{\Delta V}\right)-H_{\mathrm{HP}}(s) \underline{i}_{\mathrm{C}} \quad \Longleftarrow$ voltage control

$H_{\mathrm{HP}}(s)=\frac{k_{\mathrm{v}} s}{s+\alpha_{\mathrm{v}}} \quad \Longleftarrow$ high-pass filter

$\underline{i}_{\mathrm{C}}^{*}=\frac{1}{\alpha L_{\mathrm{f}}}\left[\left(V_{0}+\underline{\Delta V}\right)-\underline{v}_{\mathrm{F}}-j \omega_{0} L_{\mathrm{f}} \underline{i}_{\mathrm{C}}-H_{\mathrm{HP}}(s) \underline{i}_{\mathrm{C}}\right]+\underline{i}_{\mathrm{C}}$ $\Longleftarrow$ current reference equation

$\underline{v}_{\mathrm{C}}^{*}=\alpha L_{\mathrm{f}}\left(\underline{i}_{\mathrm{C}}^{*}-\underline{i}_{\mathrm{C}}\right)+j \omega_{0} L_{\mathrm{f}} \underline{i}_{\mathrm{C}}+\underline{v}_{\mathrm{F}} \Longleftarrow$ current control

Although not included in this study, the PSC uses the current reference generated above - as it gives an indication of the actual current - for overcurrent limitation in the current limitation controller (CLC). A standard $d q$ current controller, tuned for a set bandwidth of $\alpha \operatorname{rad~s}^{-1}$, as given by Eq. (6), is used. In fault mode, the CLC limits the current output of the converter to $I_{\max }$ and generates a selector signal $C_{\mathrm{Lim}}$ to disable the power synchronization and switch to conventional PLL-based synchronization. However, in normal mode $\left(|I|<I_{\max }\right)$, Eqs. (5) and (6) simplify to Eq. (3), for voltage control as described above. The PSC has demonstrated strong performance in weak networks.

\subsubsection{Distributed PLL-based (dPLL) control}

Contrary to power-synchronization implemented in VSG and PSC, the dPLL control structure, based on Yu et al. (2018) and shown in Fig. 2c, uses voltage-based synchronization by using a PLL for frequency control. Originally developed for DRU-connected OWPPs, the real power controller is used to generate the $d$-axis voltage reference as power flow is determined by offshore voltage, and a droop controller regulates frequency to share the DRU reactive power demand. Instead of the conventional approach of setting the $q$-axis voltage reference to 0 , since the PLL output can be used as an indication of frequency deviation, a frequency control loop characterized by Eq. (7), is embedded in the $q$ axis.

$v_{\mathrm{fq}}^{*}=k_{\mathrm{f}}\left(f^{*}-f\right)$

Yu et al. (2018) demonstrate frequency controllability with plug-and-play capability, providing successful sequential start-up of the GFM WTs and automatic synchronization of the offline WTs during connection with minimal impact to supply the var required to energize transformers and filters and finally ramp up the offshore voltage and start delivering active power to the onshore grid. However, only the start-up and synchronization of an islanded OWPP to an energized onshore synchronous power system via a DRU-HVDC link is studied, while the energization of export cable and onshore converter, expected from a black-start service provider, was not looked into.

\subsubsection{Direct power control (DPC)}

Lastly, a control scheme based on direct power control, originally introduced by Noguchi et al. (1998), has been implemented. In DPC, the instantaneous powers are controlled without requiring AC voltage sensors, PLL or an inner current controller, by using a look-up table and hysteresis comparators on the power errors to select the optimum switching state of the converter. Since then it has undergone many enhancements to deliver improved performance like using space vector modulation for constant switching frequency, employing sliding mode control for robustness and model predictive control for the multivariable case. The implementation used in this study is based on an improved DPC described in Gui et al. (2019), in which grid-voltage modulation allows linearization of the original non-linear system, 

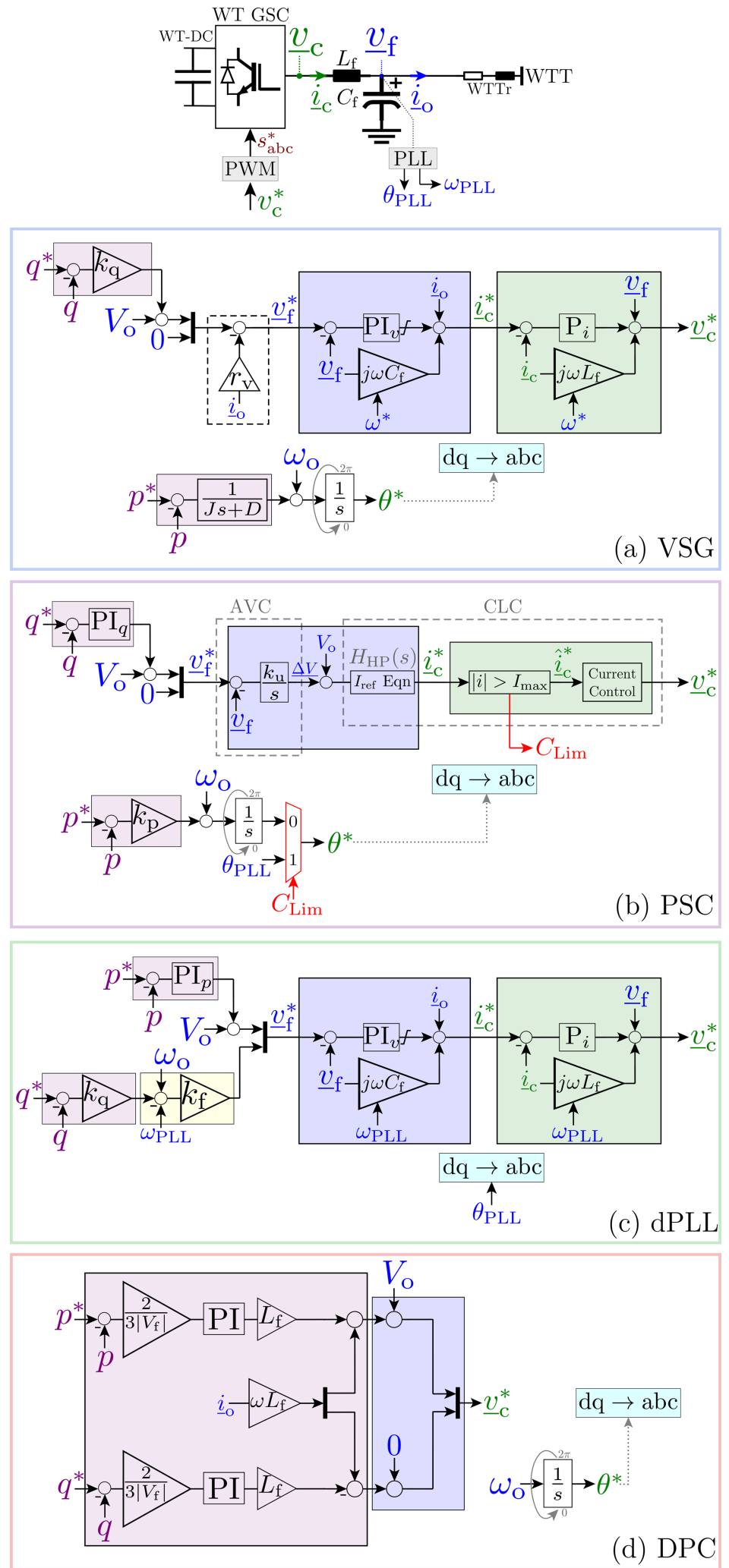

Figure 2. Control structure for (a) virtual synchronous generator (VSG), (b) power synchronization control (PSC), (c) distributed PLL-based (dPLL) control, and (d) direct power control (DPC) GFM strategies. The coloured boxes match the different blocks with their function (blue is voltage control, green is current control, and purple is power control) in the general GFM control structure, given in Fig. 1. 
resulting in ease of control design and good transient response and steady-state performance. The control structure, as shown in Fig. 2d, has been derived in Gui et al. (2019) using the instantaneous pq theory (Akagi et al., 2017) and results in a standard VSC $d q$ current control structure without the need for a PLL. In the GFM control implementation for this study, the voltage reference is given in place of the grid voltage magnitude, and a virtual phase angle is used in place of PLL-generated voltage phase angle, based on Cheng and Nian (2016).

The block schemes of the four GFM control strategies explained above, viz. VSG, PSC, dPLL, and DPC, are shown in Fig. 2. In the figure, vectors are denoted by $\underline{x}=x_{\mathrm{d}}+j x_{\mathrm{q}}$, while scalars are denoted by $x / X$. The controls are implemented in per unit. The coloured boxes in Fig. 2 show how the different blocks of each control scheme fit functionally blue for voltage control, green for current control, and purple for power control - into the general control structure presented in Fig. 1 and explained in Sect. 3.1.

\section{Model description}

A model of the system schematic shown in Fig. 3 and based on Sakamuri et al. (2019) has been developed in PSCAD. It consists of a $400 \mathrm{MW}$ GFM OWPP connected to the onshore AC grid by means of a $200 \mathrm{~km}$ long $1200 \mathrm{MW} \pm 320 \mathrm{kV}$ symmetrical monopole point-to-point HVDC link, as shown in Fig. 3a.

A detailed equivalent model has been used for the halfbridge modular multilevel converters (MMCs) of both terminals of the VSC-HVDC link. This represents each submodule as an equivalent circuit model for simplification while solving the network and then converting back to the sub-modules, thus giving a fast solution along with information about what happens inside the sub-modules. The offshore terminal (T2) MMC is controlled in GFL mode since the offshore AC network voltage is formed by the GFM OWPP, so the converter regulates the HVDC link voltage $V_{\mathrm{DC}}$ and reactive power injection $Q_{2}$ into T2. At the onshore terminal (T1), the MMC is controlled in GFM mode to regulate the onshore AC voltage magnitude $V_{1}$ and frequency $f_{1}$, in the scope of the black-start case study performed in this paper. The MMC models used have standard MMC inner control loops, such as cell voltage balancing and circulating current suppression, and the control structure for the $V_{\mathrm{DC}}-Q_{2}$ (for T2) and $V_{1}-f_{1}$ (for T1) modes can be seen in Sakamuri et al. (2019). Frequency-dependent (phase) models of PSCAD are used for the HVDC export cable. The HVDC converter transformer models include magnetic characteristics such as saturation and inrush current. Finally a pre-insertion resistor (PIR) that is bypassed after a pre-insertion time (PIT) by using coordinated mainauxiliary breakers (MB-ABs) is used for limiting the tran- sient magnetic-inrush current peak during hard-switching energization of the HVDC transformer.

The OWPP consists of 50 Type-4 (fully rated PEC interface) $8 \mathrm{MW}$ WTs, as a partially aggregated model shown in Fig. 3b, based on Muljadi et al. (2008). It consists of nine individual $\mathrm{WT}_{1-9}$ models on the first string, the second string with $\mathrm{WT}_{10-18}$ aggregated into a $72 \mathrm{MW}$ WT model, and the remaining $\mathrm{WT}_{19-50}$ aggregated into one $256 \mathrm{MW}$ model. Coupled $\pi$-section models are used for the $66 \mathrm{kV}$ array cables. Lastly the WT is modelled as a GFM unit operating in islanded mode, and so the grid-side converter (GSC) is modelled as a voltage source (average model) controlled by the four different GFM strategies, viz. VSG, PSC, dPLL, and DPC, that are explained in Sect. 3.2. This is shown in Fig. 3c.

\subsection{Assumptions}

Several simplifications have been made, mainly removing modelling details deemed not relevant for this study.

Firstly, the WT rotor-side converter (RSC) and changes to the turbine controller that are required for GFM operation have not been modelled. In conventional GFL operation of the WT, the RSC is controlled to extract maximum power from the generator while the GSC maintains power balance to control the DC link voltage of the back-to-back PEC interface of the WT and the reactive power output at the AC terminal. However, in GFM mode, the GSC cannot control the WT-DC link and reactive power anymore with the required generator torque and real power being set by the AC load, not the turbine controller, which now has to regulate the speed using pitch control (and especially avoid overspeeding during low AC-load and high winds). Hence the RSC control requires changes to be able to maintain the DC link voltage constant by ensuring real power balance (Pérez et al., 2019). Since the WT rotor and DC link dynamics are outside the scope of this study, the model assumes a constant WT-DC link voltage. Additionally an average voltage source model is used for the GSC with focus on dynamics not faster than the bandwidth of the inner current control loop. Moreover, the WT transformer is modelled as a pure electrical impedance $r+j x$ without any magnetic characteristics as it can be softstarted along with the WT voltage ramp-up, to avoid magnetic inrush and saturation effects.

Secondly, for this study, although power sharing between the WTs inside the WPP is controlled by including the outer power control loops, the WTs are started up simultaneously as opposed to a more realistic sequential energization, e.g. in Yu et al. (2018), as the study mainly focuses on the capabilities of the GFM OWPP as a whole, to provide blackstart services to the onshore grid while dealing with offshore network transients due to energization of the large converter transformer, HVDC converters, and export cable - in a controlled manner. This puts any synchronization dynamics of multiple GFM PEC-interfaced WTs out of the scope of this study. 


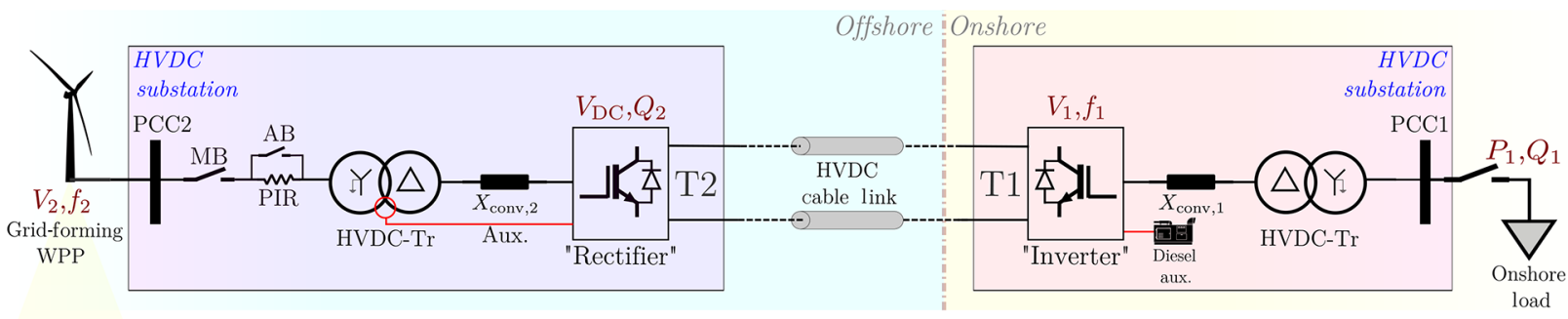

(a)

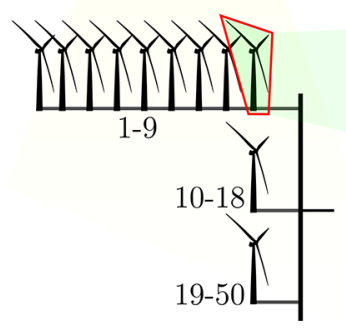

(b)

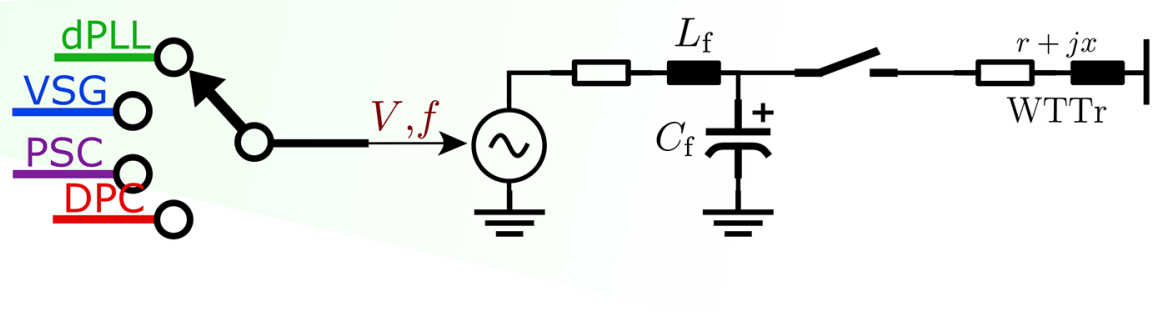

(c)

Figure 3. Schematic of the implemented PSCAD model of the system under study. This figure shows (a) the two-terminal HVDC link, with GFL offshore MMC and GFM onshore MMC, (b) the partial aggregation used to model the OWPP, and (c) the average model of the GFM WT-GSC implemented with four different control strategies operating in islanded mode.

\subsection{Controller tuning}

In this section, the tuning criteria for the control parameters of the different control schemes are presented. In a cascaded control structure, the inner loops are designed to achieve a fast response while the outer loops are tuned for regulation and stability.

Assuming a switching frequency of the wind turbine converter of $1 \mathrm{kHz}$, and with the main objective of the current controller to have a fast response, a bandwidth $(\alpha)$ of $200 \mathrm{~Hz}$ has been selected (Yazdani and Iravani, 2010). A proportional controller has been used as any steady-state error can be taken care of by the outer voltage controller. This results in the same value $\left(\alpha L_{\mathrm{f}}\right)$ of the proportional gain for VSG and dPLL, as that already used in the current control Eq. (6) for the PSC scheme.

The voltage controller on the other hand is tuned to provide zero steady-state error with a bandwidth of $40 \mathrm{~Hz}$ and a phase margin of $45^{\circ}$ (Yazdani and Iravani, 2010).

The outer power control loops are tuned to be sufficiently slower than the voltage and current controls to avoid coupling between the control levels. Since the WPP is operating in islanded mode, there is no grid to exchange power with based on a set reference; rather the real and reactive power demands are set by the load.

For the DPC, the power control loops take the form of standard vector current control, as shown in Gui et al. (2019). Since $p \propto i_{d}$ and $q \propto i_{q}$, tuning the DPC power controller is equivalent to tuning a slower current controller - a natu- ral frequency of $4 \mathrm{~Hz}$ with damping ratio of 0.74 has been chosen.

A unique control loop in the dPLL scheme is the frequency control loop that includes the cascaded voltage-current controller dynamics along with PLL, as shown in Yu et al. (2018). This requires tuning of the PLL and the controller gain $k_{\mathrm{f}}$ of Eq. (7). The PLL has been tuned to be critically damped with a bandwidth of $0.5 \mathrm{~Hz}$ - slow enough for the slow voltage controller which significantly reduces damping ( $\sim$ phase margin) in the system, moving it closer to instability. While increasing $k_{\mathrm{f}}$ leads to a faster response but with reduced damping (Yu et al., 2018), a low value was found to result in oscillations in the shared powers. As a trade-off, $k_{\mathrm{f}}$ has been tuned for the frequency control loop to have a bandwidth of $0.5 \mathrm{~Hz}$. Overall, these values ensure a high phase margin $\left(82^{\circ}\right)$ for stable operation.

Similar to the dPLL, the cascaded voltage-current controller of the VSG moves the system closer to instability at low bandwidths, due to a significant reduction in system damping ( $\sim$ phase margin). This is justified by D'Arco et al. (2013, 2015b), who show that certain eigenvalues close to the imaginary axis are sensitive to the proportional gain of the voltage controller $k_{\mathrm{pv}}$, with higher values improving the stability of the system. Moreover, lower switching frequencies seem to shift the root locus closer to imaginary axis, restricting the range of stable operating points. Sun et al. (2019) show the complexity associated with tuning VSG for damping the different oscillations, implicitly caused due to 
coupling terms in the state-space matrix. While virtual resistance helps damp the intrinsic synchronous mode of a single droop-controlled VSC, it introduces coupling between active and reactive powers, especially for multiple paralleled VSCs. The inertia term $J$ can then be tuned to provide further attenuation, but this introduces sub-synchronous oscillations which deteriorate with increased inertia. Finally according to Sun et al. (2019), since smaller droop gains reduce the inter-oscillations, values for $D$ and $k_{\mathrm{q}}$ from D'Arco et al. (2015b) have been taken as initial estimates and then fine-tuned for stable operation. It is important to note that improving one oscillation mode can trigger another and that the tuning strategy used for a single VSG might not be applicable to multiple VSGs (Sun et al., 2019). Consequently the VSG control strategy implemented here - with a swing equation - has been found to be limited in its damping of oscillations. With a slow voltage controller - smaller $k_{\mathrm{pv}}-$ the sub-synchronous mode moves closer to origin, while the synchronous mode improves in damping (D'Arco et al., 2015b). So the voltage controller has been set to the lowest possible bandwidth $(\sim 150 \mathrm{~Hz})$ while ensuring good damping and stable operation, with appropriately tuned outer loops.

The complete set of tuned parameter values are listed in Table A2.

\section{Simulation results}

In this section, the results of the dynamic simulations performed in PSCAD are presented. The energization sequence, events of which are described in detail in Table 1, is based on Sakamuri et al. (2019), but includes an extra stage of DCside controlled pre-charging of the onshore MMC cells along with the outer power control loops enabled for real and reactive power sharing amongst the WTs inside the WPP. The entire sequence is simulated; however, the main focus is on testing the characteristics of the different control strategies in enabling the OWPP to deal with the energization transients - so we focus on the real and reactive power outputs of the WPP and the voltage and frequency at the offshore PCC-2. Hard-switching is used here despite the advantages of softstart energization, as the former is more demanding on the GFM OWPP in terms of the transients linked to energization of transformers, cables, and the HVDC link.

Figure 4 shows the waveforms for the real and reactive power outputs of the WPP during the different stages of the energization sequence. Since the GFM OWPP is operating in islanded mode, the real and reactive power demand is set by the load, which depends on the particular stage of energization. For Stage 2, it is the reactive power required for magnetic energization of the offshore HVDC transformer and $A C$-side pre-charging of the offshore MMC cells. A PIR is inserted for PIT duration to limit the inrush peak. In Stage 3, power is required to energize the HVDC cable when the offshore MMC is de-blocked to control the HVDC link voltage, while in Stage 4, the $D C$-side pre-charging of the onshore MMC cells draws power from the OWPP to maintain the energy balance on the HVDC link. Finally the OWPP supplies power to match the onshore block load in Stage 6. It is clear from the $P Q$ waveforms shown in Fig. 4 that there are some differences in the transient behaviour of the four control strategies, despite having an overall similar profile. PSC and VSG show a delayed response, as indicated by the delayed peaks, in Stages 2 (at 1.6 s), 3, and 4a and b. This is due to the right-half-plane zero in the closed-loop transfer function $\frac{\Delta P}{\Delta \theta}(s)$ for the power-based synchronization methods, as shown in Zhang et al. (2010). The dPLL shows a synchronous and sub-synchronous mode getting excited at Stage $4 \mathrm{~b}$ probably due to a change in system coupling. However this is damped after some time due to the current control. Finally the DPC, due to its overall standard current control structure, shows good damping of oscillations, as apart from overcurrent limitation the current controller's function is also to damp resonance modes (Zhang, 2010).

Since the scope of this study is to focus on the OWPP behaviour as an AC voltage source during the different stages of energization, the waveforms for the voltage and frequency at the offshore PCC-2 are presented in Figs. 5 and 6, respectively. The GFM WPP, controlled as an AC voltage source, has different characteristics based on the control method used. The $V$ waveform in Fig. 5 shows that the OWPP with the four different GFM controls can successfully energize the transformer, cables, and MMC cells and supply the onshore load, while maintaining a stable voltage at the offshore PCC2 , with the transient distortions during the different stages being recovered fast by the GFM controls.

An interesting observation in Fig. 5 is that during Stage 4, there is oscillation in the voltage for VSG, which transiently increases as the active power increases (Fig. 4) with frequency decreasing at 2.5 and $2.8 \mathrm{~s} \mathrm{(Fig.} \mathrm{6).} \mathrm{This} \mathrm{is} \mathrm{linked} \mathrm{to}$ the energy imbalance in the HVDC link as the offshore MMC cells discharge during the charging of onshore MMC cells, to which the WPP then reacts by producing the required active power and absorbing the reactive power generated from the capacitor charging, as shown by the negative var curves in Fig. 4 - Stages $4 a$ and b. Comparing with synchronous generators, this can be understood similar to transient rotorangle instability during large load changes in weak networks, which in our case is due to virtual resistance and a transient change in network coupling during capacitor charging. To enhance stability of the VSG, a virtual automatic voltage regulator (AVR) can be used like in synchronous generators and is the work of future studies.

Having looked at voltage, the other key aspect of the gridforming WPP is its frequency response. The frequency waveform in Fig. 6 shows significant differences in the frequency transients, highlighting the frequency control characteristics of the different grid-forming methods, although overall the frequency swing is in the range of $49.8-50.2 \mathrm{~Hz}$, except in Stage 1. 
Table 1. Simulation events of the energization sequence.

\begin{tabular}{lrl}
\hline Stage & Time (s) & Events \\
\hline 1 & 0 & WTs energized simultaneously and operating in GFM mode. \\
\hline 2 & 1.3 & $\begin{array}{l}\text { GFM WPP is connected to energize PCC-2, and MB is closed to insert PIR for energizing } \\
\text { the offshore HVDC transformer and pre-charging the offshore MMC cells. }\end{array}$ \\
\hline 3 & 2.6 & PIR is bypassed after PIT (=0.3 s) by closing AB. \\
\hline 4 & 2.5 & Offshore MMC is de-blocked to control the HVDC voltage - HVDC link is energized. \\
& 2.8 & $\begin{array}{l}\text { (b) Controlled pre-charging of onshore MMCs upper-arm cells with lower arm bypassed. } \\
\text { (c) Controlled pre-charging of onshore MMC finished; both arms blocked. }\end{array}$ \\
\hline 5 & 3.3 & Onshore MMC is de-blocked to control voltage and frequency - onshore AC PCC-1 is energized. \\
\hline 6 & 4 & Onshore 30 MW block load is connected. \\
\hline
\end{tabular}

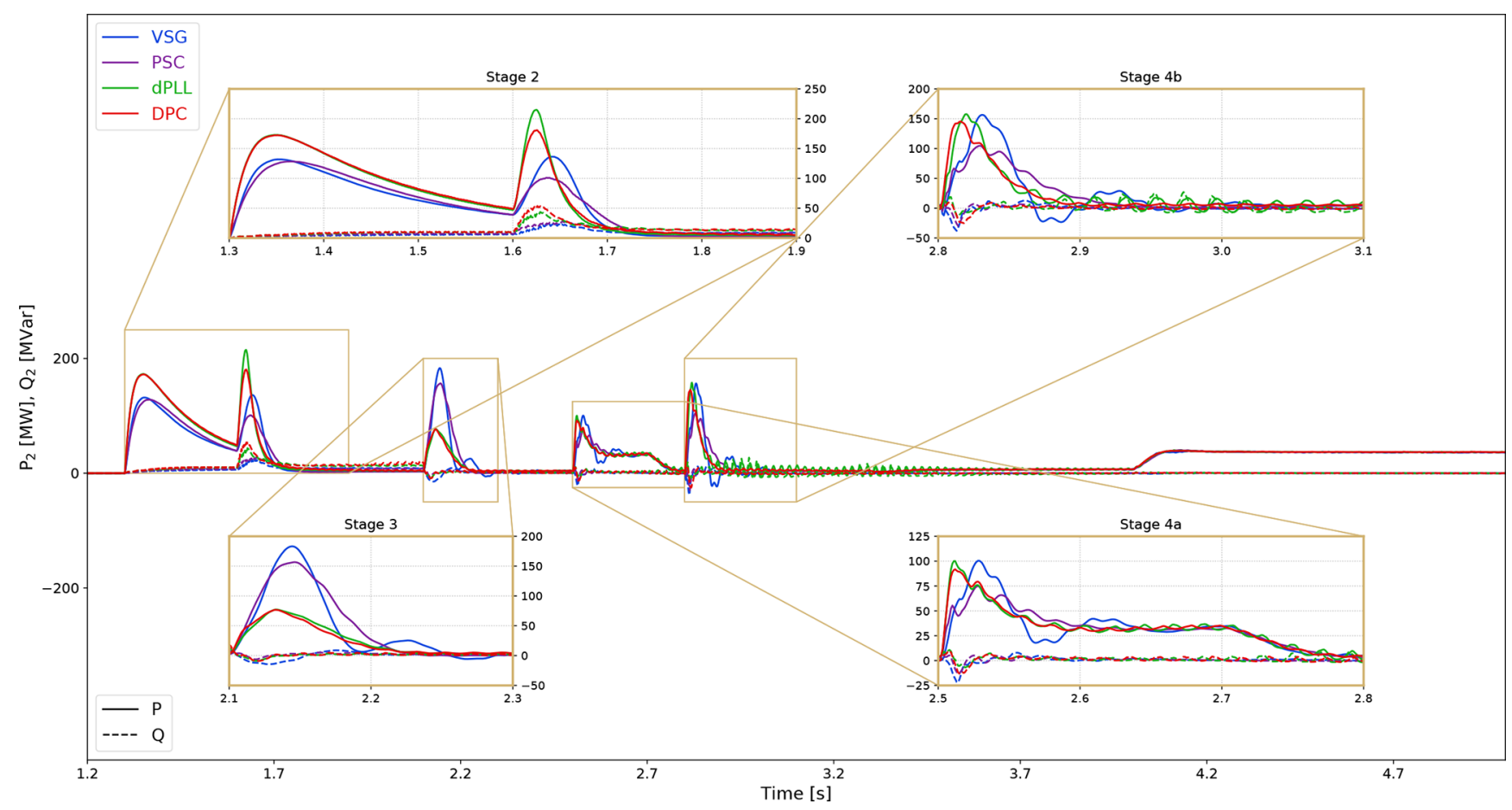

Figure 4. Real (solid line) and reactive (dotted line) power output of the offshore WPP with zoomed insets to show transients in selected stages of the energization sequence.

At startup (Stage 1), there is a high-frequency swing due to simultaneous connection of all GFM WTs. Although this would be avoided in reality due to sequential connection of WTs, it gives a glimpse into the characteristics of the different control methods. The VSG and dPLL, with standard cascaded voltage-current control, show reduced damping at such low bandwidths, as discussed in Sect. 4.2. Although the VSG has inertia that provides additional attenuation, it introduces a sub-synchronous resonance mode that can be seen in the later stages. The PSC has integral control in its voltage loop to suppress the high-frequency disturbances along with a high-pass filter for damping the resonant modes. Moreover, since the DPC has the standard vector current control structure, it has a well-damped response.

In Stage 2, the event at $1.6 \mathrm{~s}$ is quite demanding in terms of the power peak for dPLL and DPC and is associated with a large frequency swing, especially for dPLL due to reduced system damping from the low-bandwidth cascaded controller. For the power-synchronization controls, viz. PSC and VSG, their active damping characteristic or inertia helps slow down the swing. However, looking closely at $1.6 \mathrm{~s}$ (Stage 2) in Fig. 6, the effect of the right-half-plane zero, al- 

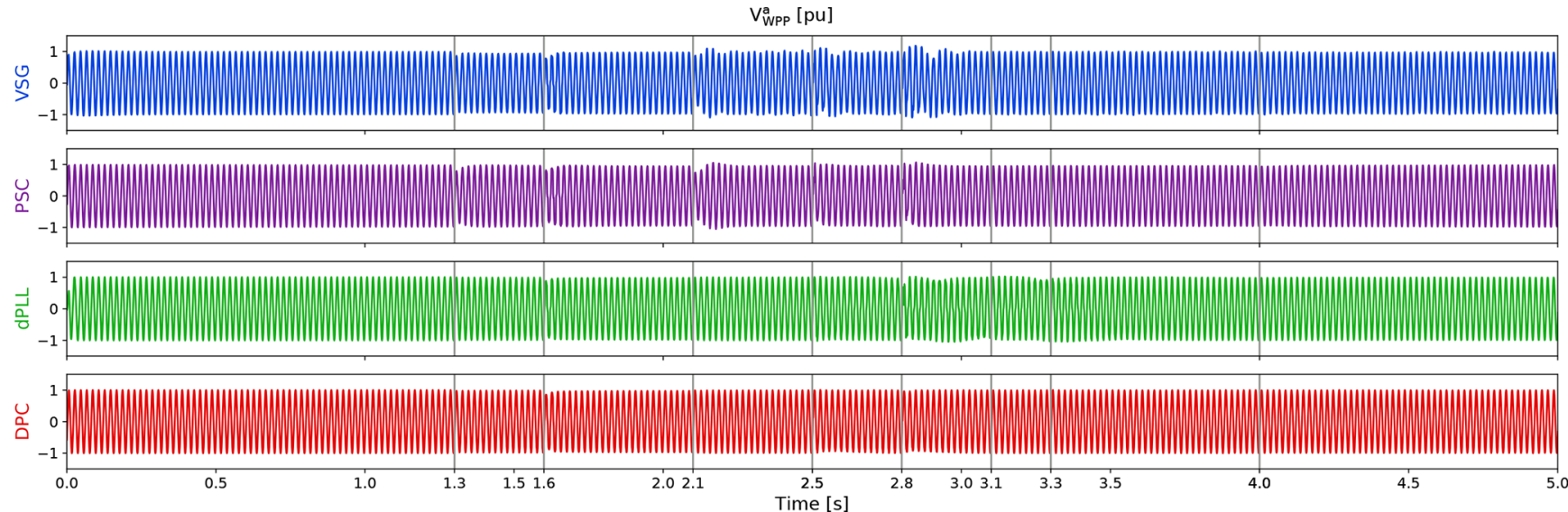

Figure 5. WPP output phase voltage (pu) for the different GFM control schemes.

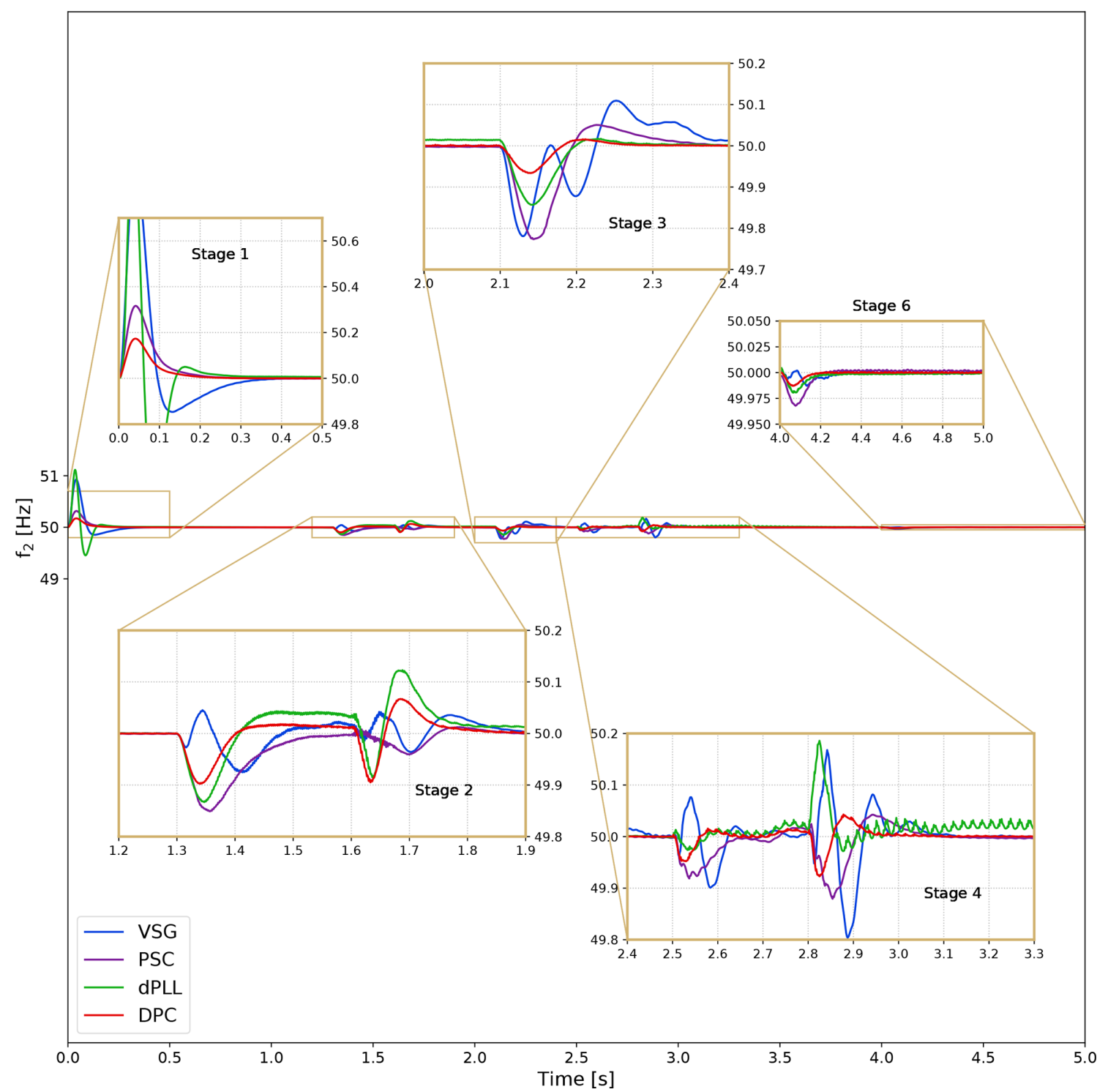

Figure 6. Frequency at offshore PCC-2 with zoomed insets to show transients in the different stages of the energization sequence. 
though well damped, can be seen in the non-minimum phase behaviour.

In Stages 3 and 4, the power-synchronization-based methods, viz. PSC and VSG, have the largest swing in frequency and power due to the capacitors in the circuit being charged, resulting in negative var for the WPP and a changed coupling in the circuit. This shows that power-synchronization-based methods are prone to oscillation when the system coupling is changed. Lastly, the DPC has no closed-loop voltage control but just standard current control with a virtual phase angle and shows superior performance, compared to the other control schemes. This indicates that having decoupling feedforward terms in the voltage loop can deteriorate the performance, especially during energization of capacitive loads that change the networks' coupling in the initial stages of black start. However, although DPC works well in islanded mode, future studies are needed to investigate its behaviour during synchronization transients and faults.

Overall the VSG control shows oscillatory behaviour in all stages. This is due to the reduced damping in the system for low bandwidth cascaded voltage-current control. As discussed in Sect. 4.2, although virtual resistance damps the synchronous oscillations, it changes the coupling, leading to more resonance modes. Inertia has been tuned to provide additional damping, but it introduces a low-frequency mode, which is excited in all the different stages in Fig. 6. Sun et al. (2019) show that oscillation damping by modifying outer power control loops - using a derivative term for lead-lag controller, or with adaptive feed-forward compensation - can avoid requirement of virtual impedance and damp oscillations more flexibly. The frequency swing is most pronounced in Stage $4 \mathrm{~b}$ at $2.8 \mathrm{~s}$ when the onshore MMC lower-arm cells are pre-charged. This event also triggers a near- $50 \mathrm{~Hz}$ oscillation for the dPLL due to the reduced damping, again as a consequence of the standard cascaded control structure with low bandwidths. These oscillations will be more damped for greater values of resistance in the system. It is important to note here that no auxiliary load has been simulated, and the WT converter equivalent resistance is considered to be 0 . Thus, system damping is limited only to losses and transformer resistance.

\section{Conclusions}

Recent field tests on HVDC interconnectors have shown that VSC-HVDC can be used for black-start services. This makes VSC-HVDC-connected offshore wind power plants promising candidates for providing black-start and islanding operation capabilities, as conventional generation is being phased out and wind power plants grow bigger to meet the decarbonization aims. This paper presents an analysis of the transient behaviour of an HVDC-connected offshore wind power plant participating in a traditional bottom-up power system restoration procedure and focuses on grid-forming as the main control change required to enable black-start and islanding services from wind turbines. The general working principle of grid-forming control has been explained with the constituent functional blocks, along with a conceptual explanation of four different techniques, viz. virtual synchronous generator, power synchronization control, distributed PLLbased control, and direct power control. These methods were then implemented and compared in a study of the black start of onshore load by an HVDC-connected offshore wind power plant, focusing on transients due to energization of transformers, cables, MMC cells, and an HVDC link.

The simulation results show that all four methods are able to deal with the energization transients in a controlled manner while maintaining stability of voltage and frequency at the offshore terminal. However, differences in their transient behaviours were observed and a qualitative discussion was presented. It has been shown that the low bandwidth of standard cascaded control structure - in VSG and dPLL - reduces system damping, pushing the system closer to instability. Moreover, the performance of power-synchronization-based methods - viz. VSG and PSC - depends on the network coupling and can deteriorate for capacitive loads. Finally the lack of any decoupling terms in the voltage control - for PSC and DPC - results in a superior performance, as the network is weak, with less clear decoupling between the traditional $P-f$ and $Q-V$ inter-dependencies. While the results presented in this paper provide an initial comparison between the different grid-forming control strategies, further investigation is needed, especially in regards to harmonic load sharing, synchronization transients during sequential energization of wind turbines inside the wind power plant, and the effect of black-start and islanded operation on rotor and turbine DC link dynamics, before concluding on the best control approach for black-starting the wind turbines. Lastly auxiliary load is expected to improve performance, by enhancing the damping in the system, which is critical in the initial stages of black start, and should be modelled. 
Appendix A: Parameters

Table A1. Main circuit parameters of the model (T2 - offshore, T1 - onshore, $X_{\mathrm{L}}$ - leakage reactance).

\begin{tabular}{ll}
\hline Parameters & Values \\
\hline WT rating & $8 \mathrm{MW}, 66 \mathrm{kV}$ \\
\hline WT GSC filter & $L_{\mathrm{f}}=10 \%, C_{\mathrm{f}}=5 \%$ \\
\hline WT transformer & $0.69 / 66 \mathrm{kV}$ \\
\hline & $R=1 \%, X_{\mathrm{L}}=1 \%$ \\
WPP rating & $400 \mathrm{MW}$ \\
\hline HVDC transformers & $1200 \mathrm{MVA}, X_{\mathrm{L}}=15 \%$ \\
& $\mathrm{~T} 2: 66 / 390 \mathrm{kV}$ \\
& $\mathrm{T} 1: 390 / 400 \mathrm{kV}$ \\
\hline PIR, PIT & $120 \Omega, 0.3 \mathrm{~s}$ \\
\hline HVDC link rating & $\pm 320 \mathrm{kV}, 1200 \mathrm{MW}, 200 \mathrm{~km}$ \\
\hline MMC & $1200 \mathrm{MVA}$ \\
\hline Onshore load & $225 \mathrm{submodules} \mathrm{per} \mathrm{arm}$ \\
\hline
\end{tabular}

Table A2. Tuned control parameter values in per unit.

\begin{tabular}{lll}
\hline Control & Parameters & Values \\
\hline VSG & $\mathrm{P}_{i}$ & 0.4 \\
& $\mathrm{PI}_{v}$ & $0.11,2.55$ \\
& $r_{\mathrm{V}}$ & 0.2 \\
& $J$ & $2 \times 10^{3}$ \\
& $D$ & $4 \times 10^{5}$ \\
& $k_{\mathrm{q}}$ & 0 \\
\hline PSC & $r_{\mathrm{V}}, \alpha_{\mathrm{V}}$ & $0.5,40$ \\
& $r_{\mathrm{u}}$ & 0.8 \\
& $k_{\mathrm{p}}$ & 0.004 \\
& $\mathrm{PI}_{q}$ & $1,0.01$ \\
\hline $\mathrm{dPLL}$ & $\mathrm{P}_{i}$ & 0.4 \\
& $\mathrm{PI}_{v}$ & $0.02,2.55$ \\
& $\mathrm{PI}_{\mathrm{PLL}}$ & 10,25 \\
& $k_{\mathrm{f}}$ & 50 \\
& $\mathrm{PI}_{p}$ & 4,40 \\
& $k_{\mathrm{q}}$ & 0.01 \\
\hline DPC & $\mathrm{PI}$ & $0.012,0.21$ \\
\hline
\end{tabular}

\section{Appendix B: Nomenclature}

dPLL Distributed PLL-based control

DPC Direct power control

DRU Diode rectifier unit

GFL Grid-following control

GFM Grid-forming control

GSC Grid side converter

HVAC High-voltage alternating-current

HVDC High-voltage direct-current

(O)WPP (Offshore) wind power plant

PCC Point of common coupling

PEC Power electronic converter

PIR Pre-insertion resistor

PIT Pre-insertion time

PLL Phase-locked loop

PSC Power synchronization control

VSC Voltage source converter

VSG Virtual synchronous generator control

WT Wind turbine 
Code and data availability. Inquiries about data and requests for access to the simulation models used in this study should be directed to the authors.

Author contributions. JNS designed the simulation for the case study. AJ and JNS implemented the models and carried out the simulations. NAC and AJ analysed the results. AJ prepared the manuscript with contributions from NAC and JNS.

Competing interests. The authors declare that no competing interests are present.

Special issue statement. This article is part of the special issue "Wind Energy Science Conference 2019". It is a result of the Wind Energy Science Conference 2019, Cork, Ireland, 17-20 June 2019.

Acknowledgements. The authors gratefully acknowledge the contributions of Oscar Saborío-Romano to the discussions leading up to this work.

Financial support. This work is part of the InnoDC project (https://innodc.org/, last access: 1 October 2020) that has received funding from the European Union's Horizon 2020 Research and Innovation programme under the Marie Skłodowska-Curie grant agreement no. 765585 .

Review statement. This paper was edited by Ola Carlson and reviewed by two anonymous referees.

\section{References}

Akagi, H., Watanabe, E. H., and Aredes, M.: Instantaneous Power Theory and Applications to Power Conditioning, 2nd edn., John Wiley \& Sons, Inc., Hoboken, New Jersey,2017.

Aktarujjaman, M., Kashem, M., Negnevitsky, M., and Ledwich, G.: Black start with DFIG based distributed generation after major emergencies, in: 2006 IEEE International Conference on Power Electronic, Drives and Energy Systems, 1-6, 2006.

Andersen, B. and Xu, L.: Hybrid HVDC System for Power Transmission to Island Networks, IEEE Transactions on Power Delivery, 19, 1884-1890, 2004.

Arbab-Zavar, B., Palacios-Garcia, E. J., Vasquez, J. C., and Guerrero, J. M.: Smart Inverters for Microgrid Applications: A Review, Energies, 12, 840, 2019.

Arghir, C., Jouini, T., and Dörfler, F.: Grid-forming Control for Power Converters based on Matching of Synchronous Machines, Automatica, 95, 273-282, 2018.

Aten, M., Shanahan, R., Mosallat, F., and Wijesinghe, S.: Dynamic Simulations of a Black Starting Offshore Wind Farm Using Grid Forming Converters, in: 18th Wind Integration Workshop, Energynautics GmbH, Dublin, 2019.
Australian Energy Market Operator: Black system, South Australia, 28 September 2016 - Final Report, 2017.

Bahrman, M. and Bjorklund, P.-E.: The New Black Start: System Restoration with Help from Voltage-Sourced Converters, IEEE Power and Energy Magazine, 12, 44-53, 2014.

Beck, H. P. and Hesse, R.: Virtual synchronous machine, in: 9th International Conference on Electrical Power Quality and Utilisation, EPQU, Barcelona, 2007.

Becker, H., Naranovich, A., Hennig, T., Akbulut, A., Mende, D., Stock, S., and Hofmann, L.: System restoration using VSCHVDC connected offshore wind power plant as black-start unit, in: 2017 19th European Conference on Power Electronics and Applications (EPE'17 ECCE Europe), 2017.

Blasco-Gimenez, R., Añó-Villalba, S., Rodríguez-D’Derlée, J., Morant, F., and Bernal-Perez, S.: Distributed voltage and frequency control of offshore wind farms connected with a diodebased HVdc link, IEEE Transactions on Power Electronics, 25, 3095-3105, 2010.

Cai, L., Karaagac, U., and Mahseredjian, J.: Simulation of Startup Sequence of an Offshore Wind Farm with MMC-HVDC Grid Connection, IEEE Transactions on Power Delivery, 32, 638-646, https://doi.org/10.1109/TPWRD.2016.2517184, 2017.

Chen, Z., Guerrero, J. M., and Blaabjerg, F.: A Review of the State of the Art of Power Electronics for Wind Turbines, IEEE Transactions on Power Electronics, 24, 1859-1875, 2009.

Cheng, P. and Nian, H.: Direct power control of voltage source inverter in a virtual synchronous reference frame during frequency variation and network unbalance, IET Power Electronics, 9, 502511, https://doi.org/10.1049/iet-pel.2015.0219, 2016.

D'Arco, S. and Suul, J. A.: Virtual synchronous machines - Classification of implementations and analysis of equivalence to droop controllers for microgrids, in: 2013 IEEE PES PowerTech, Grenoble, 2013.

D’Arco, S., Suul, J. A., and Fosso, O. B.: Control system tuning and stability analysis of Virtual Synchronous Machines, in: 2013 IEEE Energy Conversion Congress and Exposition, ECCE 2013, IEEE, Denver, CO, https://doi.org/10.1109/ECCE.2013.6647045, 2664-2671, 2013.

D'Arco, S., Suul, J. A., and Fosso, O. B.: A Virtual Synchronous Machine implementation for distributed control of power converters in SmartGrids, Electric Power Systems Research, 122, 180-197, 2015a.

D'Arco, S., Suul, J. A., and Fosso, O. B.: Automatic Tuning of Cascaded Controllers for Power Converters Using Eigenvalue Parametric Sensitivities, IEEE Transactions on Industry Applications, 51, 1743-1753, https://doi.org/10.1109/TIA.2014.2354732, 2015b.

De Boeck, S., Van Hertem, D., Das, K., Sørensen, P. E., Trovato, V., Turunen, J., and Halat, M.: Review of Defence Plans in Europe: Current Status, Strengths and Opportunities, CIGRE Transactions on Science \& Engineering, 5, 6-16, 2016.

Elia: Study on the Review of the Black Start Ancillary Services, 2018.

El-Zonkoly, A.: Integration of wind power for optimal power system black-start restoration, Turkish Journal of Electrical Engineering \& Computer Sciences, 23, 1853-1866, 2015.

European Parliament and Council of the European Union: Directive (EU) 2018/2001 of the European Parliament and of the Council 
on the promotion of the use of energy from renewable sources (recast), Official Journal of the European Union, L 328, 82-209, 2018.

Göksu, Ö., Saborío-Romano, O., Cutululis, N. A., and Sørensen, P.: Black Start and Island Operation Capabilities of Wind Power Plants, in: 16th Wind Integration Workshop, Berlin, Germany, 2017.

Green, T. C. and Prodanović, M.: Control of inverter-based micro-grids, Electric Power Systems Research, 77, 1204-1213, https://doi.org/10.1016/j.epsr.2006.08.017, 2007.

Guerrero, J. M., Vasquez, J. C., Matas, J., De Vicuña, L. G., and Castilla, M.: Hierarchical control of droop-controlled AC and DC microgrids - A general approach toward standardization, IEEE Transactions on Industrial Electronics, 58, 158-172, 2011.

Gui, Y., Wang, X., and Blaabjerg, F.: Vector Current Control Derived from Direct Power Control for Grid-Connected Inverters, IEEE Transactions on Power Electronics, 34, 9224-9235, 2019.

Jain, A., Das, K., Göksu, Ö., and Cutululis, N. A.: Control Solutions for Blackstart Capability and Islanding Operation of Offshore Wind Power Plants, in: Proceedings of the 17th International Wind Integration workshop, Energynautics GmbH, Stockholm, 2018.

Jain, A., Sakamuri, J. N., Das, K., Göksu, Ö., and Cutululis, N. A.: Functional Requirements for Blackstart and Power System Restoration from Wind Power Plants, in: 2nd International Conference on Large-Scale Grid Integration of Renewable Energy in India, Energynautics GmbH, New Delhi, 2019.

Jiang-Hafner, Y., Duchen, H., Karlsson, M., Ronstrom, L., and Abrahamsson, B.: HVDC with voltage source converters - A powerful standby black start facility, in: Transmission and Distribution Exposition Conference: 2008 IEEE PES Powering Toward the Future, PIMS 2008, 2008.

Johnson, B., Rodriguez, M., Sinha, M., and Dhople, S.: Comparison of virtual oscillator and droop control, in: 2017 IEEE 18th Workshop on Control and Modeling for Power Electronics (COMPEL), IEEE, 2017.

Kanellos, F. D. and Hatziargyriou, N. D.: Control of Variable Speed Wind Turbines in Islanded Mode of Operation, IEEE Transactions on Energy Conversion, 23, 535-543, https://doi.org/10.1109/TEC.2010.2048216, 2008.

Lu, L. and Cutululis, N. A.: Virtual synchronous machine control for wind turbines : a review, in: 16th Deep Sea Offshore Wind R\&D conference (DeepWind), IOP Publishing, Trondheim, https://doi.org/10.1088/1742-6596/1356/1/012028, 2019.

Martínez-Turégano, J., Año-Villalba, S., Bernal-Pérez, S., Peña, R., and Blasco-Gimenez, R.: Mixed Grid-Forming and GridFollowing Wind Power Plants for Black Start Operation, in: 17th International Wind Integration Workshop, Energynautics GmbH, Stockholm, 2018.

Muljadi, E., Pasupulati, S., Ellis, A., and Kosterov, D.: Method of equivalencing for a large wind power plant with multiple turbine representation, in: 2008 IEEE Power and Energy Society General Meeting - Conversion and Delivery of Electrical Energy in the 21st Century, 2008.

National Grid: Technical Report on the events of 9 August 2019, 2019a.

National Grid: Black Start from Non-Traditional Generation Technologies, $2019 \mathrm{~b}$.
Noguchi, T., Tomiki, H., Kondo, S., and Takahashi, I.: Direct power control of PWM converter without power-source voltage sensors, IEEE Transactions on Industry Applications, 34, 473-479, 1998.

Pérez, A. N. F., Sun, Y., Burstein, A. W., Harson, A., and Tang, B.: Co-simulation Hardware in the Loop Test bench for a Wind Turbine: Validation of a wind turbine black start capability, in: 18th Wind Integration Workshop, Energynautics GmbH, Dublin, 2019.

Pogaku, N., Prodanović, M., and Green, T. C.: Modeling, analysis and testing of autonomous operation of an inverter-based microgrid, IEEE Transactions on Power Electronics, 22, 613-625, 2007.

Rocabert, J., Luna, A., Blaabjerg, F., and Rodriguez, P.: Control of Power Converters in AC Microgrids, IEEE Transactions on Power Electronics, 27, 4734-4749, 2012.

Sakamuri, J. N., Göksu, Ö., Bidadfar, A., Saborío-Romano, O., Jain, A., and Cutululis, N. A.: Black Start by HVdc-connected Offshore Wind Power Plants, in: IECON 2019 - 45th Annual Conference of the IEEE Industrial Electronics Society, Lisbon, 2019.

Sarkar, M. N. I., Meegahapola, L. G., and Datta, M.: Reactive Power Management in Renewable Rich Power Grids: A Review of Grid-Codes, Renewable Generators, Support Devices, Control Strategies and Optimization Algorithms, IEEE Access, 6, 41 458-41 489, 2018.

Schyvens, T.: Interactions Between Transmission System Connected Converters, in: IEEE Power and Energy Society General Meeting, Atlanta, GA, 2019.

Seca, L., Costa, H., Moreira, C. L., and Pecas Lopes, J. A.: An innovative strategy for power system restoration using utility scale wind parks, in: Proceedings of IREP Symposium: Bulk Power System Dynamics and Control - IX Optimization, Security and Control of the Emerging Power Grid, IREP 2013, 2013.

Sørensen, T. B., Kwon, J. B., and Jørgensen, J. M.: A live black start test of an HVAC network using soft start capability of a voltage source HVDC converter, in: CIGRE 2019 Aalborg Symposium, 2019.

Sun, C., Joos, G., and Bouffard, F.: Identification of low-frequency oscillation mode and improved damping design for virtual synchronous machines in microgrid, IET Generation, Transmission and Distribution, 13, 2993-3001, https://doi.org/10.1049/ietgtd.2018.7066, 2019.

Tavner, P.: Offshore Wind Turbines: Reliability, availability and maintenance, Institution Of Engineering \& Technology (IET), 2012.

Tayyebi, A., Dörfler, F., Miletic, Z., Kupzog, F., and Hribernik, W.: Grid-Forming Converters - Inevitability, Control Strategies and Challenges in Future Grids Application, in: CIRED Workshop 2018, Ljubljana, 2018.

van Wesenbeeck, M. P., de Haan, S. W., Varela, P., and Visscher, K.: Grid tied converter with virtual kinetic storage, in: 2009 IEEE PowerTech Conference, 1-7, Bucharest, 2009.

Yazdani, A. and Iravani, R.: Voltage-Sourced Converters in Power Systems, John Wiley \& Sons, Inc., Hoboken, New Jersey, https://doi.org/10.1002/9780470551578, 2010.

Yu, L., Li, R., and Xu, L.: Distributed PLL-based Control of Offshore Wind Turbine Connected with Diode-Rectifier based HVDC Systems, IEEE Transactions on Power Delivery, 33, 1328-1336, 2018. 
Zeni, L., Hesselbaek, B., Sorensen, P. E., Hansen, A. D., and Kjaer, P. C.: Control of VSC-HVDC in offshore AC islands with wind power plants: Comparison of two alternatives, 2015 IEEE PowerTech Conference, 2015.

Zhang, L.: Modeling and Control of VSC-HVDC Links Connected to Weak AC Systems, Ph.D. thesis, Royal Institute of Technology (KTH), Stockholm, Sweden, 2010.

Zhang, L., Harnefors, L., and Nee, H. P.: Power-synchronization control of grid-connected voltage-source converters, IEEE Transactions on Power Systems, 25, 809-820, 2010.
Zhong, Q.-c. and Weiss, G.: Static Synchronous Generators for Distributed Generation and Renewable Energy, in: 2009 IEEE/PES Power Systems Conference and Exposition, 1-6, 2009.

Zhu, L., Pan, Z., and Xu, G.: Black Start with DFIG-Based Wind Turbines Using Improved Virtual Synchronous Control, in: 2018 21st International Conference on Electrical Machines and Systems (ICEMS 2018), KIEE EMECS (KIEE Electrical Machinery and Energy Conversion Systems), 2018. 